\title{
Computer Self-Efficacy: A Practical Indicator of Student Computer Competency in Introductory IS Courses
}

\author{
Rex Karsten \& Roberta M. Roth \\ University of Northern lowa (USA)
}

Karsten@uni.edu, Roth@uni.edu

ABSTRACT

Students often receive their first college-level computer training in introductory information systems courses. Students and faculty frequently expect this training to develop a level of student computer competence that will support computer use in future courses. In this study, we applied measures of computer self-efficacy to students in a typical introductory IS course. The measures provided useful evidence that student perceptions of their ability to use computers effectively in the future significantly improved as a result of their training experience. The computer self-efficacy measures also provided enhanced insight into course-related factors of practical concern to IS educators. Study results also suggest computer self-efficacy measures may be a practical and informative means of assessing computer-training outcomes in the introductory IS course context.

Keywords: Computer Self-Efficacy, Self-Efficacy, IS Education

\section{Introduction}

Business colleges commonly require business majors to complete an introductory information systems (IS) course early in their program of study (Kim \& Keith, 1994). It is in the context of introductory IS courses that many students first receive formal, college-level training in the computer hardware and software they are likely to encounter in future education and business environments (Omar, 1991). While the computer training offered in such courses is generally quite basic in nature, a number of business school constituencies have a substantial stake in course outcomes. Students, instructors in other disciplines, and IS instructors often expect introductory IS courses to instill the "fundamentals" necessary for effective computer use and acquisition of additional computer skills in future courses (Kim \& Keith, 1994). As IS instructors, we have also observed that skill development expectations are often accompanied by expectations of enhanced student motivation to use computers in other course settings as a result of the training (Larson \& Smith, 1994). In sum, students are expected to become more computer literate, as well as more inclined to seek opportunities to use computers to solve problems in the future.

We propose that meeting reasonable expectations regarding student computer competence and confidence is an appropriate course outcome objective for introductory IS courses. Unfortunately, we have found it difficult to determine and demonstrate the degree to which computer training in the introductory courses accomplishes this objective. Traditional methods of course assessment provide relatively limited insight into the development of student computer capability. For example, grades may indicate that certain performance criteria and standards have been met. However, course grades contribute little information about student confidence or motivation to use computers in subsequent courses or employment settings. Moreover, grades and other traditional assessment measures are generally determined during or after the course. Consequently, they are limited in their ability to provide information regarding the impact of a variety of factors (e.g., gender, prior computer experience) of interest to IS educators on the development or enhancement of computer competency and student confidence in the introductory course context.

\section{Purpose of the Study}

Recognizing the limitations of traditional measures of assessment, the purpose of this study was to expand our insight into student computer competency and confidence in introductory IS courses from an IS educator's perspective. In this study, we have applied and evaluated a measure of computer self-efficacy as a supplementary introductory IS course assessment tool. Computer self-efficacy is based on the well-researched concept of self-efficacy - the belief one has the capability to perform a specific task (Bandura, 1997). Prior research consistently indicates that computer 


\section{CSE: A Practical Indicator of Student Computer Competency}

self-efficacy (CSE) is positively correlated with an individual's willingness to choose and participate in computer-related activities, expectations of success in such activities, and persistence or effective coping behaviors when faced with computer-related difficulties (Compeau \& Higgins, 1995; Gist, Schwoerer, \& Rosen, 1989; Murphy, Coover, \& Owen, 1989). In short, CSE appears to "capture" much of what we hope are desirable student outcomes of introductory IS courses. Moreover, CSE lends itself to meaningful measurement and has been demonstrated to be discriminative and informative in similar training circumstances (Harrison \& Ranier, 1992; Murphy et al., 1989; Torkzadeh \& Koufteros, 1994).

A review of the literature indicates CSE has been investigated in similar settings; however, it has not been thoroughly investigated as an additional assessment tool in this important educational context. In this investigation of CSE from a course assessment perspective, a measure of CSE before and after students completed an introductory IS course was taken. The impact of training and other individual and situational factors of practical concern to IS educators on CSE was analyzed. In addition, the possible role CSE measures might play in course assessment was evaluated. Our main purpose was to enhance our understanding of student computer training outcomes in the introductory IS course context. This study also responds to regular calls for continuing research into the relationship among a variety of individual and situational variables, computer self-efficacy, and the development of computer skills (Compeau \& Higgins, 1995; Murphy et al., 1989; Torkzadeh \& Koufteros, 1994).

\section{Computer Self-Efficacy}

Self-efficacy is the belief one has capability to perform a specific task (Bandura, 1997). Correspondingly, computer self-efficacy “....refers to a judgment of one's capability to use a computer" (Compeau \& Higgins, 1995, p. 192). It has been proposed that individuals base self-efficacy judgments on four main sources of information (discussed below) that vary in appraisal value (Bandura, 1997). Individuals weigh the contributions of these sources of information and generate a self-appraisal of their capability to perform the behavior of interest (Murphy et al., 1989). Individuals who perceive themselves capable of performing certain tasks or activities are defined as high in self-efficacy and are more likely to attempt and execute these tasks and activities.

People who perceive themselves as less capable are less likely to attempt and execute these tasks and activities, and are accordingly defined as lower in self-efficacy (Barling \& Beattie, 1983; Bandura, Adams, \& Beyer, 1977).
The four sources of information considered essential to selfefficacy evaluation are consistently available in a typical introductory IS course. Therefore, the construct appears very relevant to our understanding of computer training outcomes in the introductory IS course context. These four information sources are briefly described below in decreasing order of influence (Bandura, 1997).

- Students gather the most important source of CSE information, personal performance accomplishments, via frequent computer exercises and laboratory activities requiring regular demonstration of computer hardware and software understanding and proficiency.

- Opportunities are also available for observations of the successes and failures of others. Students have regular occasion to witness the successes and failures of fellow students who provide standards against which they compare their own performance. In somewhat similar fashion, instructors also model successful computerrelated behaviors, and consequently provide another standard of comparison that allows self-efficacy appraisal (Gist, Schwoerer, \& Rosen, 1989).

- Self-efficacy information is also regularly delivered through verbal persuasion. Students receive suggestions or exhortations from instructors and/or fellow students that encourage and support their computer skill development, and reinforce the notion that they are, or can become, computer competent.

- Students may acquire self-efficacy information from physiological indices (Schunk, 1984). Trembling or sweating prior to an in-class computer exercise might be interpreted by students as a sign that they would not do well. On the other hand, a lack of such symptoms could be perceived as a sign of confidence and/or competence. Hands-on quizzes in the computer lab, for example, are noted for engendering a variety of such physical symptoms.

\section{Relevant Computer Self-Efficacy Research}

Several research studies have investigated the relationship of CSE to computer training and other individual and situational variables of interest to educators. These studies are briefly summarized below.

The investigation of CSE and computer training has focused on how and/or who delivers self-efficacy information to trainees, which we will refer to as Instructional Style. In a 
study of the effects of training method on CSE and performance with computer software, individuals high in CSE performed better when skills were delivered via a behavioral model, whereas individuals low in CSE performed better when provided with an interactive tutorial (Gist et al., 1989). In another study, significant increases in CSE were found for students receiving standard classroom instruction in an introductory computer science course, but no significant increase in CSE was found for students also receiving additional verbal persuasion (Smith, 1994). Similarly, significant increases in student CSE were found following completion of an undergraduate course in computers and information processing that employed both lecture and laboratory instruction (Torkzadeh \& Koufteros, 1994).

Research has also focused on the relationship of a number of individual and situational variables to CSE. The relationship of Gender to CSE has been of regular interest, since gender differences in self-efficacy have been found in other skill areas characterized as "masculine" in nature (Murphy et al., 1989). Gender findings have been mixed. A study of knowledge workers at a large university found that males evidenced higher CSE than females (Harrison \& Ranier, 1992). In a study involving an undergraduate course in computers and information processing, gender differences were found to be limited to one of several CSE factors measured prior to computer training (Torkzadeh \& Koufteros, 1994). No gender differences were found on a measure of computer task self-efficacy among university students enrolled in an introductory computer science course (Smith, 1994), or in a study examining graduate students, adult vocational students, and professionals (nurses) in three different computer training settings (Murphy et al., 1989).

The relationship of Computer Experience to CSE has also been investigated. Not surprisingly, individuals with prior computer experience are more likely to evidence higher levels of CSE than individuals without such experience (Harrison \& Ranier, 1992; Hill, Smith, \& Mann, 1987).

Finally, researchers have examined the connection between CSE and several other behaviors of interest to educators. For example, research has found evidence of a positive relationship between CSE and registration in college-level computer courses (Hill et al., 1987), decisions to use computers (Compeau \& Higgins, 1995; Hill et al., 1987), and performance in software training (Gist et al., 1989).

\section{Computer Self-Efficacy Measures}

CSE measures employed in other training settings have employed several different scales of varying length and approach (Compeau \& Higgins, 1995; Gist et al., 1989; Murphy et al., 1989). The measure deemed most applicable to this study was the Computer Self-Efficacy Scale (CSES) (Murphy et al., 1989). CSES is based on prior self-efficacy research (Bandura, 1997) and has been validated elsewhere (Torkzadeh \& Koufteros, 1994). The CSES was chosen as the most appropriate measure for our research for several reasons. First, other researchers have proposed the scale as an appropriate measure of skill attainment both before and after training (Murphy et al., 1989). Additionally, the CSES has been demonstrated to be meaningfully discriminative in studies employing similar subjects (Harrison \& Ranier, 1992; Murphy et al., 1989; Torkzadeh \& Koufteros, 1994). Perhaps most importantly, the CSES most closely reflected the nature of the basic computer skills students had the opportunity to develop in our introductory IS course. The CSES, slightly modified to incorporate three basic network skill items that reflect training specific to our course, is provided in Appendix 1.

\section{Method}

\section{Design}

The impact of computer training in our introductory IS course on CSE was investigated using perceptual responses collected from undergraduate student participants. The selfefficacy measures were completed in-class during the first week of class (prior to computer training exposure) and the last week of class. Basic demographic data were also collected. While measures were coded for later comparison, participants were guaranteed confidentiality and that data would not be examined until final grades for the course had been issued. The responses of students who did not complete both sets of measures were discarded.

\section{Participants}

The research sample consisted of students enrolled in three sections of an undergraduate Introduction to Information Systems course offered in the business college of a mediumsize midwestern university. The course was required for all business majors. All sections consisted of 45 hours of inclass instruction, identical syllabi, exercises, homework, and exams. Course content and structure were typical of introductory IS courses currently offered in business schools. The course was designed to provide students an opportunity to develop or enhance their knowledge of and hands-on facility with appropriate computer hardware and software. The laboratory portion of the class was integrated with lecture topics, and provided at least 15 hours of hands-on experience with microcomputer applications, including 


\section{CSE: A Practical Indicator of Student Computer Competency}

operating systems, programming, spreadsheet analysis, and database software.

A total of 156 students volunteered to participate in the study. Eight students were dropped from the analysis because they did not complete both pretest and posttest measures, leaving 148 participants. Sample demographic data is displayed in Table 1.

\section{Table 1: Demographics}

\begin{tabular}{|c|c|c|}
\hline Total \# of Participan & & 148 \\
\hline Gender & $\underline{\mathbf{N}}$ & $\underline{\%}$ \\
\hline$\overline{\text { Males }}$ & 84 & $56.8 \%$ \\
\hline Females & $\underline{64}$ & $43.2 \%$ \\
\hline & $\overline{148}$ & $100 \%$ \\
\hline Major & & \\
\hline Business Majors & 120 & $81.1 \%$ \\
\hline NonBusiness Majors & $\underline{28}$ & $18.9 \%$ \\
\hline & 148 & $100 \%$ \\
\hline Class & & \\
\hline$\overline{\text { Fresh }}$ & 10 & $6.8 \%$ \\
\hline Soph & 85 & $57.4 \%$ \\
\hline Junior & 46 & $31.1 \%$ \\
\hline Senior & 7 & $4.7 \%$ \\
\hline & 148 & $100 \%$ \\
\hline$\underline{\text { Age }}$ & & \\
\hline$\overline{\text { Years }}<19$ & 5 & $3.4 \%$ \\
\hline Years $19-20$ & 100 & $67.6 \%$ \\
\hline Years $21-22$ & 20 & $13.5 \%$ \\
\hline Years > 22 & 23 & $15.5 \%$ \\
\hline & $\overline{148}$ & $100 \%$ \\
\hline Mean & Median & Mode \\
\hline 21.5 & 20 & 20 \\
\hline Computer Experien & & \\
\hline Years $<2$ & 64 & $43.2 \%$ \\
\hline Years 2-3 & 32 & $21.6 \%$ \\
\hline Years 4-5 & 23 & $15.5 \%$ \\
\hline Years $>5$ & 29 & $20.2 \%$ \\
\hline & $\overline{148}$ & $100 \%$ \\
\hline Mean & Median & Mode \\
\hline 2.99 & 2.0 & 1.0 \\
\hline
\end{tabular}

As would be expected in a required business course, the majority $(81.1 \%)$ of study participants was business majors. Eighty-four participants (56.8\%) were male, and 64 (43.2\%) were female. Participants' ages ranged from 18 to 48 years. The mean age of participants was 21.5 years, with two-thirds $(67.6 \%)$ either 19 or 20 years of age (mode $=20$ years of age). Accordingly, nearly ninety percent (88.5\%) were sophomores or juniors. Computer experience prior to course enrollment ranged from 0 to 14 years, with over sixty percent $(64.8 \%)$ of study participants reporting three or less years prior experience with computers (mode $=1$ year of experience).

\section{Measures}

As described previously, the Computer Self-Efficacy Scale (CSES) was employed as both the pretest and posttest measure of computer self-efficacy. The Likert-scale items ranged from "1" (Strongly Disagree) to "5" (Strongly Agree). As worded, a higher score on an item indicated a greater degree of confidence in that element of the basic skill set assessed by the scale. A computed mean score of all test items was used to represent the pretest and the posttest measures of computer self-efficacy. The measures of computer self-efficacy are henceforth referred to as pretest or posttest CSE, respectively.

\section{Variables}

The variables selected for study were based on our review of the relevant CSE research, our practical concerns as IS educators, and their availability for meaningful measurement. Formal hypotheses were not offered because findings in other training settings were often mixed, or did not specify an order of entry or a direction of variable impact that was clearly applicable in this study context.

Based on previously-discussed research, we included the following independent variables: Gender (Harrison \& Ranier, 1992; Murphy et al., 1989; Torkzadeh \& Koufteros, 1994); self-reported years of Computer Experience (Harrison \& Ranier, 1992; Hill et al., 1987); and Instructional Style (Gist et al., 1989). The latter variable was included since it is common to have numerous instructors teaching the same introductory course. In this instance, three different instructional styles were possible. Individual instructors taught two sections and two sections were team-taught. While course materials, content, and format were identical, the possibility existed that the personal characteristics or teaching styles of individual instructors could influence the manner in which information was provided or received (Gist et al., 1989).

In addition, we included two variables based on our practical concerns as IS instructors: Course Length and Major. Many colleges offer versions of traditional semesterlong courses that compress the same number of instructional hours into a shortened time frame (e.g., 16-week regular semester courses vs. 8-week summer courses). While the number of instructional hours remains constant, the 
compressed version limits the amount of time available to assimilate or master the course content. On the other hand, the intensity of the shorter session might enhance student CSE. Regardless of the direction of the effect, we felt Course Length is a reasonable concern and included it as a factor in our analysis.

Major was included because of the unexpected number of nonbusiness majors in the study sample. We wished to determine if computer training emphasizing business applications would have a different impact on the computer self-efficacy of students in business and nonbusiness majors. The variable Major was coded to reflect these two categories.

Finally, a single-item measure of students' perceptions of their ability to learn computer-related skills in subsequent courses, termed Posttest Confidence, was gathered for comparison with posttest CSES. If the introductory IS course experience enhanced student CSE, it seems reasonable that this confidence should also be reflected in student attitudes toward acquiring future computer skills.

\section{Data Analyses}

The relationship of gender and prior computer experience with initial student perceptions of CSE was evaluated. A two-tailed t-test was used to determine if any significant mean differences based on gender were evident on pretest CSES scores. Correlational analysis was performed to determine if a significant correlation existed between reported years of computer experience and pretest CSES scores. Correlational analysis was also used to determine the relationship between posttest CSES and students' confidence in their ability to learn the computer skills required in future courses. In order to assess the impact of the computer training on student CSE, a two-tailed t-test was employed to determine if significant differences existed between pretest and posttest CSES scores.

Since no formal hypotheses were offered and the literature review suggested no particular order of precedence for the variables examined, stepwise multiple regression analysis was used to investigate the impact of gender, computer experience, course length, and instructional style on the dependent variable, posttest CSE. As a means of ensuring reliability (Cohen \& Cohen, 1975), the pretest CSES score was entered first as a covariate. Since no significant pretest CSE score by factor interactions were observed in separate regression tests, the necessary ANCOVA assumption of parallel regression slopes was satisfied.

\section{Results and Discussion}

\section{Pretest Findings}

As displayed in Table 2, there was no significant difference in student pretest CSE based on gender. The pretest CSE scores for male $(M=3.34)$ and female $(M=3.38)$ students did not differ significantly $(p>$.676). The lack of a gender effect may be attributable to the fact that our study sample was predominantly comprised of traditional students who are products of a strong, state-wide school system that provides similar opportunities for male and female students to gain computer experience. Perhaps gender differences are more likely to occur in more non-traditional samples (Harrison \& Ranier, 1992) where, ironically, more "traditional" conceptions of what constitutes masculine and feminine tasks may be more likely to exist.

\section{Table 2: t-test Analysis for Gender Differences on Pretest CSE}

\begin{tabular}{|c|c|c|}
\hline Gender: & Male & Female \\
\hline $\mathrm{N}$ & 84 & 64 \\
\hline $\begin{array}{l}\text { Mean Pretest } \\
\text { CSE }\end{array}$ & 3.34 & 3.38 \\
\hline $\begin{array}{l}\text { SD } \\
\text { t-value }\end{array}$ & .67 & $\begin{array}{c}.51 \\
-0.42\end{array}$ \\
\hline & $=$ & .676 \\
\hline
\end{tabular}

Prior computer experience was significantly correlated with initial student perceptions of CSE. As shown in Table 3, the number of years of prior computer experience was significantly and positively correlated with the pretest CSES scores $(\mathrm{r}=.391, \mathrm{p}<.001)$. As would be expected, students with more computer experience tend to have higher initial levels of CSE.

\section{Table 3: Correlational Analysis, Pretest CSE with Computer Experience}

$\begin{array}{lcrrr}\text { Variables } & \text { Mean } & \text { SD } & \boldsymbol{r} & \boldsymbol{p} \\ \text { Pretest CSE } & 3.35 & .60 & & \\ \text { Computer } & 3.02 & 2.97 & & \mathbf{. 0 0 0} * \\ \begin{array}{l}\text { Experience } \\ \text { (Years) }\end{array} & & & \mathbf{. 3 9 1} & \end{array}$

$* \mathrm{p}<.001$

\section{Posttest Findings}

It was satisfying to find that the computer training had a positive impact on the CSE of students completing the introductory IS course. As Table 4 shows, the posttest CSE scores of students $(M=4.36)$ were significantly higher than 


\section{CSE: A Practical Indicator of Student Computer Competency}

pretest CSE scores $(M=3.35, p<.001)$. The CSE measure was originally selected because it appeared to assess the basic computer skills taught in the course. Therefore, the positive results suggest the computer competency objectives of the course are being accomplished. Students completing the course have a greater sense of computer self-efficacy than when they began. Note also that while both pretest and posttest CSE measures are subjective self-assessments, students received regular objective measures of their computer competencies via graded laboratory exercises, homework assignments, and exams. We believe it reasonable to assume that this final measure of perceived computer self-efficacy reflects these more objective forms of feedback as well.

\section{Table 4: t-test Analyses for Pretest-Posttest CSE Differences}

$\begin{array}{lcccc}\text { All Students } & \text { Iean } & \text { SD } & \begin{array}{l}\text { t- } \\ \text { value }\end{array} & \boldsymbol{p} \\ \text { Pretest CSE } & 3.35 & .60 & & \\ \begin{array}{l}\text { Posttest CSE } \\ \text { Business Majors }\end{array} & 4.36 & .39 & 23.4 & \mathbf{. 0 0 0 *} \\ \begin{array}{l}\text { Pretest CSE } \\ \text { Posttest CSE }\end{array} & 3.33 & .61 & & \\ \text { NonBusiness } & 4.40 & .37 & 21.9 & \mathbf{. 0 0 0 *} \\ \begin{array}{l}\text { Majors } \\ \text { Pretest CSE }\end{array} & & & & \\ \text { Posttest CSE } & 3.46 & .59 & & \\ & 4.23 & .44 & 8.3 & \mathbf{. 0 0 0 *} \\ & & & & * \mathrm{p}<.001\end{array}$

The result of the stepwise multiple regression analysis is shown in Table 5. After entering the covariate, pretest CSE, only student major entered as a significant model component. None of the other variables - gender $(p>.632)$, course length $(\mathrm{p}>.472)$, instructional style (represented by dummy variables D1 and D2), or computer experience ( $p>$ .711) - demonstrated a significant relationship with the dependent variable, posttest CSE.

It is admittedly difficult to base any conclusions on the absence of significant findings. However, the lack of a gender influence on CSE is gratifying and consistent with pretest results. It is also satisfying to note that course length (at least between 16-week and 8-week sessions) and instructor style were not significant sources of CSE differences. Additional research would be necessary to determine if there is a course length "threshold" above or below which the development of CSE might be affected.

The finding that prior computer experience is not significantly associated with final levels of CSE is interesting. Several explanations are offered. First, the pretest CSE variable, which is correlated with computer experience, may be masking the effect of computer experience. The second explanation is compatible with the first. Prior computer experience was self-reported by participants. While more years of experience may have contributed to a higher pre-course self-appraisal of CSE, this may not have been an accurate estimate of the prior computer experience relevant to the computer skill developed in this course. For example, a survey of a similar population indicates that although college students are increasingly computer-experienced, that experience is often narrow in focus (e.g., word processing) (Larson \& Smith,

Table 5: Stepwise Multiple Regression Results (DV = Posttest CSE)

$\begin{array}{ll}\text { Multiple R } & .5551 \\ \text { R Square } & .3082 \\ \text { Adjusted R Square } & .2982 \\ \text { Standard Error } & .3297 \\ & \\ \text { F }=30.9672 & \text { Significance of }=. \text {.000* }^{*}\end{array}$

Variables in the Equation

\begin{tabular}{lccl}
\hline & $\mathrm{B}$ & $\mathrm{T}$ & $\mathrm{S}$ \\
Pretest CSE & .3409 & 7.476 & $\mathbf{. 0 0 0 0} *$ \\
Major & -.2157 & -3.090 & $\mathbf{. 0 0 2 4} * *$ \\
(Constant) & 3.4855 & 20.452 & .0000
\end{tabular}

Variables Not in the Equation

\begin{tabular}{|c|c|c|c|}
\hline & $\begin{array}{l}\text { Beta } \\
\text { In }\end{array}$ & $\mathrm{T}$ & Sig T \\
\hline Gender & -.0338 & -0.479 & .6328 \\
\hline Course Length & .0641 & 0.720 & .4726 \\
\hline $\begin{array}{l}\text { Computer Experi- } \\
\text { ence }\end{array}$ & .0512 & 0.608 & .5439 \\
\hline D1 (Instructional & -.0623 & -0.825 & .4106 \\
\hline D2 Style) & .0943 & 1.312 & .1917 \\
\hline
\end{tabular}

1994). Finally, perhaps students with less prior-experience simply "catch up" with the more experienced students during the course, at least in terms of the basic skills that defined computer self-efficacy in this study.

The impact of student major was surprising. While all students did make significant gains in perceived computer self-efficacy, nonbusiness majors did not appear to benefit to quite the same degree as business majors. Several 
explanations appear plausible. Since the majority of class computer exercises and examples have a clear business focus, nonbusiness majors may have found them more difficult to comprehend than business majors. Also, given that the introductory IS course is required for business majors but elective for most nonbusiness majors, the varying motivations to master the software applications may explain some of the difference. While ascertaining the actual reason would require additional study, several factors lessen our concern over this finding. First, the course is clearly identified as specifically addressing business student interests. Second, regardless of major, as demonstrated in Table 4, nonbusiness students still experienced significant improvements in CSE as a result of course training (Pretest CSE $M=3.46$, Posttest CSE $M=4.23, p<.001$ ).

Finally, as IS educators would hope, student levels of CSE measured upon course completion exhibit a strong, positive correlation with the general confidence students have in their ability to learn any computer skills necessary in future courses. Table 6 shows the significant, positive correlation between posttest CSES scores and student confidence in future skill acquisition $(r=.691, p<.001)$. To the extent that enhanced self-confidence implies less reluctance to acquire computer skills in subsequent courses, it appears that an introductory IS course may provide some motivational influence as well.

\section{Table 6: Correlational Analysis, Posttest CSE with Future Skill Confidence}

$\begin{array}{lcccc}\text { Variables } & \text { Mean } & \text { SD } & \mathbf{r} & \boldsymbol{p} \\ \begin{array}{l}\text { Posttest } \\ \text { CSE }\end{array} & 4.36 & .39 & & \\ \begin{array}{l}\text { Future Skill } \\ \text { Confidence }\end{array} & 4.27 & .63 & \mathbf{. 6 9 1} & \mathbf{. 0 0 0 *}\end{array}$

$* \mathrm{p}<.001$

\section{Conclusions, Limitations, and Future Research}

Within the limitations discussed below, we believe the results of our investigation indicate that measuring student CSE has the potential to provide additional useful insights into the development of student computer competency in typical introductory IS courses. The measure employed permitted us to analyze individual and situational variables of practical importance to IS educators, whose influence is not fully revealed by conventional student and course assessment measures. Importantly, measuring student CSE appears to be a promising way to determine and to demon- strate, from the student perspective, the degree to which important computer competencies have been attained. In sum, our research suggests that appropriate measures of student CSE can contribute meaningful and demonstrable outcomes assessments information.

Noting study limitations also serves to identify avenues of future research. Our literature review indicated this study would be the most thorough investigation of the individual and situational factors associated with computer training and CSE in the introductory IS course context. However, research in related settings suggests many more variables of potential influence (Harrison \& Ranier, 1992). For example, our study sample reflected similar course enrollment at many universities. Unfortunately, the sample was too homogeneous to permit generalizations to more nontraditional student populations, or to study factors particular to more heterogeneous groups that are also likely to influence perceptions of CSE. In sum, future research is needed that considers additional variables across more diverse student populations.

Moreover, although we selected a measure of CSE that was developed and validated in similar settings (Murphy et al., 1989; Torkzadeh \& Koufteros, 1994), we recognize that other measures exist that may provide equally valuable information of a different sort and depth (Compeau \& Higgins, 1995). The measure employed was intuitively appealing, appropriate to this study's research perspective, and did provide some practical insights that conventional course outcome measures may not. A need remains for continued research to refine, analyze, and compare the several available CSE measures from both an educator's and researcher's viewpoint.

\section{References}

Bandura, A. (1997). Self-efficacy: The exercise of control. New York: W.H. Freeman \& Company.

Bandura, A., Adams, N.E., \& Beyer, J. (1977). Cognitive processes mediating behavioral change. Journal of Personality and Social Psychology, 35 (3), 125-139.

Barling, J. \& Beattie, R. (1983). Self-efficacy beliefs and sales performance. Journal of Organizational Behavior Management, 5, 41-51.

Cohen, J. \& Cohen, P. (1975). Applied multiple regression/correlational analysis for the behavioral sciences. Hillsdale, New Jersey: Lawrence Erlbaum Associates.

Compeau, D.R. \& Higgins, C.A. (1995). Computer self-efficacy: Development of a measure and initial test. MIS Quarterly, June, 189-211. 


\section{CSE: A Practical Indicator of Student Computer Competency}

Gist, M.E., Schwoerer, C., \& Rosen, B. (1989). Effects of alternative training methods on self-efficacy and performance in computer software training. Journal of Applied Psychology, 74 (6), 884-891.

Harrison, A.W. \& Ranier, K. (1992). The influence of individual differences on skill in end-user computing. Journal of Management Information Systems, Summer, 9 (1), 93-111.

Hill, T., Smith, N.D., \& Mann, M.F. (1987). Role of self-efficacy expectations in predicting the decision to use advanced technologies: The case of computers. Journal of Applied Psychology, 72 (2), 307-313.

Kim, C.S. \& Keith, N.K. (1994). Computer literacy topics: A comparison of views within a business school. Journal of Information Systems Education, Summer, 6 (2), 55-57.

Larson, J. \& Smith, M.A. (1994). An assessment of the computer literacy and computer attitudes of incoming first-year students at the University of Wisconsin-Eau Claire. Proceedings of Selected Research and Development Presentations, 1994 Na- tional Convention of the Association for Educational Communications and Technology.

Murphy, C.A., Coover, D., \& Owen, S.V. (1989). Development and validation of the computer self-efficacy scale. Educational and Psychological Measurement, 49, 893-899.

Omar, M.H. (1991). Impact of the MIS course on business students' attitudes to computers and on their understanding of information systems concepts. Journal of Computer Information Systems, Fall, 36-39.

Schunk, D.H. (1984). Self-efficacy perspective on achievement behavior. Educational Psychologist, 19, 48-58.

Smith, J.M. (1994). The effects of education on computer selfefficacy. Journal of Industrial Teacher Education, 31 (3), 5165 .

Torkzadeh, G. \& Koufteros, X. (1994). Factor validity of a computer self-efficacy scale and the impact of computer training. Educational and Psychological Measurement, 54 (3), 813821 .

\section{Appendix 1: Computer Self-Efficacy Scale (from Murphy, Coover, \& Owen, 1989)}

I feel confident entering and saving data (words and numbers) into a file.

I feel confident calling up a data file to view on a monitor screen.

I feel confident storing software correctly.

I feel confident handling a floppy disk correctly.

I feel confident escaping/exiting from a program or software.

I feel confident making selections from an on-screen menu.

I feel confident copying an individual file.

I feel confident using the computer to write a letter or essay.

I feel confident moving the cursor around the monitor screen.

I feel confident working on a personal computer (microcomputer).

I feel confident using a printer to make a "hardcopy" of my work.

I feel confident getting rid of files when they are no longer needed.

I feel confident copying a disk.

I feel confident adding and deleting information to and from a data file.

I feel confident getting software up and running.

I feel confident organizing and managing files.

I feel confident understanding terms/words relating to computer software.
I feel confident understanding terms/words relating to computer hardware.

I feel confident describing the function of computer hardware (keyboard, monitor, disk drives, processing unit).

I feel confident troubleshooting computer problems.

I feel confident explaining why a program (software) will or will not run on a given computer)

I feel confident understanding the three stages of data processing: input, processing, output.

I feel confident learning to use a variety of programs (software).

I feel confident using the computer to analyze number data.

I feel confident learning advanced skills within a specific program (software).

I feel confident using the computer to organize information. I feel confident writing simple programs for the computer.

I feel confident using the user's guide when help is needed.

I feel confident getting help for problems in the computer system.

I feel confident logging onto a mainframe computer system.

I feel confident logging off a mainframe computer system.

I feel confident working on a mainframe computer.

I feel confident logging onto a computer network.

I feel confident logging off a computer network.

I feel confident working on a computer network. 